\title{
Acúmulo de matéria seca e nutrientes no capim-mombaça em função do manejo da adubação nitrogenada
}

\author{
Fernando Shintate Galindo ${ }^{1}$, Salatiér Buzetti ${ }^{1}$, Marcelo Carvalho Minhoto Teixeira Filho ${ }^{1}$, \\ Elisângela Dupas², Mariana Gaioto Ziolkowski Ludkiewicz ${ }^{1}$
}

\author{
${ }^{1}$ Universidade Estadual Paulista Júlio de Mesquita Filho, Câmpus de Ilha Solteira, Ilha Solteira, São Paulo, Brasil. E-mail: \\ fs.galindo@bol.com.br, sbuzetti@agr.feis.unesp.br, mcmtf@yahoo.com.br, mariana.gaioto@gmail.com \\ ${ }^{2}$ Universidade Federal da Grande Dourados, Dourados, Mato Grosso do Sul, Brasil. E-mail: elidupas@gmail.com \\ Recebido: 29/09/2017; Aceito: 18/04/2018
}

\section{RESUMO}

O nitrogênio é um elemento de extrema importância na cultura de forrageiras, sendo o nutriente que mais influencia na produtividade e na qualidade das pastagens. Objetivou-se estudar a condução de uma pastagem com alto potencial produtivo utilizando fontes e doses de nitrogênio. As fontes de $\mathrm{N}$ foram nitrato de amônio (N.A.) e ureia aplicadas nas doses de N: 0, 50, 100, 150 e $200 \mathrm{~kg} \mathrm{ha}^{-1}$ por corte, na espécie forrageira Panicum maximum cv. Mombaça, avaliando o acúmulo de nitrogênio $(\mathrm{N})$, fósforo $(\mathrm{P})$ e potássio $(\mathrm{K})$ e a taxa de acúmulo de matéria seca (MS). As fontes de $\mathrm{N}$ não influenciaram o acúmulo de $\mathrm{N}, \mathrm{P}$ e K e taxa de acúmulo de MS. As doses influenciaram positivamente no acúmulo de $\mathrm{N}, \mathrm{K}$ e a taxa de acúmulo de MS, ocorrendo incremento com o aumento das doses de $\mathrm{N}$. Como as fontes de $\mathrm{N}$ não influenciaram os atributos analisados recomenda-se o uso da ureia por ser o fertilizante de maior concentração de $\mathrm{N}$ e de menor relação custo por unidade de nutriente, na dose de $100 \mathrm{~kg} \mathrm{ha}^{-1}$, propiciando maior acúmulo de nutrientes e ganho na MS, além da manutenção do capim-mombaça.

Palavras-chave: gramínea tropical, nitrato de amônio, pastagem, ureia

\section{Dry matter and nutrients accumulation in mombasa guineagrass in function of nitrogen fertilization management}

\begin{abstract}
The nitrogen is an element extremely important in forage, being the nutrient more influence on productivity and quality of pasture. The objective was to study a pasture with high yield potential using sources and rates of nitrogen. Nitrogen sources were ammonium nitrate and urea, as $\mathrm{N}$ rates:0, 50, 100, 150 and $200 \mathrm{~kg} \mathrm{ha}^{-1}$ per harvest), in Mombasa guineagrass (Panicum maximum cv. Mombaça), quantifying the accumulation of nutrients nitrogen $(\mathrm{N})$, phosphorus $(\mathrm{P})$ and potassium $(\mathrm{K})$ and the rate of accumulation of dry matter (DM). Sources of $\mathrm{N}$ did not affect the accumulation of $\mathrm{N}, \mathrm{P}$ and $\mathrm{K}$ and the rate of accumulation of dry matter (DM). $\mathrm{N}$ rates positively influenced the accumulation of nutrients $\mathrm{N}$ and $\mathrm{K}$ and the rate of accumulation of dry matter (DM), occurring increase with increasing doses of $\mathrm{N}$. As nitrogen sources did not influence the general attributes analyzed, it recommends to use urea as a source of $\mathrm{N}$ fertilizer to be the largest concentration of $\mathrm{N}$ and lower cost per unit of nutrient, at a dose of $100 \mathrm{~kg} \mathrm{ha}^{-1}$, providing increase of nutrient accumulation, DM and maintenance of Mombasa guineagrass.
\end{abstract}

Key-words: tropical grass, ammonium nitrate, pasture, urea. 


\section{Introdução}

O Brasil possui entre 180 a 200 milhões de hectares de pastagens e possui um dos maiores rebanhos comerciais de bovinos do mundo (Silva et al., 2009; Dupas et al., 2016; Galindo et al., 2017). Assim, as pastagens no Brasil são extremamente importantes para a produção de carne bovina devido à ampla extensão territorial das pastagens estabelecidas no país, além de ser considerada a base do alimento do rebanho, uma vez que é a fonte mais barata para produção de proteína animal para consumo humano (Fernandes et al., 2015). Isso é possível devido a fatores climáticos que favorecem a produção de forragem nos diferentes locais e períodos do ano.

No entanto, grande parte destas se encontram em algum estado de degradação, devido à falhas na correção do solo por falta de adubação, principalmente a nitrogenada. Considerando a produção agropecuária, na sua maioria extensiva, é necessária a recuperação de tais áreas a fim de elevar a produção forrageira por meio da adubação. Para a exploração intensiva das pastagens, a correção e adubação com destaque à nitrogenada, estão entre os fatores mais importantes que determinam o nível de produção e a qualidade das pastagens (Euclides et al., 2007; Benett et al., 2008; Silveira et al., 2010; Silveira et al., 2015).

Várias espécies são utilizadas em pastagens no Brasil, dentre elas destaca-se o capim-mombaça. A espécie Panicum maximum (syn. Megathyrsus maximus) apresenta um dos maiores potenciais de produção de matéria seca (PMS) em ambientes subtropicais e tropicais conhecidos, podendo atingir produção anual de matéria seca em torno de $33 \mathrm{t} \mathrm{ha}^{-1}$ (Galindo et al., 2017). $\mathrm{O}$ manejo adequado da fertilidade do solo e o conhecimento dos requisitos nutricionais deste capim são extremamente importantes para o manejo de pastagens, o que reflete em maior produtividade $\mathrm{e}$ disponibilidade de alimentos para os animais (Barth Neto et al., 2010; Silveira et al., 2010; Pereira et al., 2012).

O nitrogênio (N) é um componente importante das proteínas, além de maximizar o rendimento da matéria seca de gramíneas forrageiras, sendo o principal nutriente para a manutenção de sua produtividade (Dupas et al., 2016). Quando aplicado, é assimilado pela planta e associado às cadeias de carbono promovendo o aumento dos constituintes celulares e, consequentemente, aumentando o vigor do rebrote e a produção total de matéria seca verde das plantas sob condições climáticas favoráveis (Galindo et al., 2017), entretanto, o efeito positivo da adubação nitrogenada sobre os teores de macronutrientes e micronutrientes no tecido da forrageira nem sempre são observados. Estudos de avaliação do aproveitamento de adubos nitrogenados, aplicados em várias épocas, são importantes, pois resultam em maior conhecimento sobre a utilização do insumo pelas culturas, viabilizando seu uso econômico. Portanto, em sistemas de produção onde se deseja trabalhar com alta eficiência de utilização da planta forrageira deve-se adotar a adubação nitrogenada satisfatória (Silva et al., 2009; Fernandes et al., 2015).

De acordo com Euclides et al. (2007), vários estudos demonstraram aumento significativo na produção do Panicum maximum com o suprimento de N. Apesar de a maioria desses experimentos apresentarem respostas lineares, as magnitudes deles são variadas. Assim, há a necessidade de se desenvolverem estudos sobre as fontes e doses de $\mathrm{N}$ aplicadas e a frequência do seu suprimento, para melhor entendimento do comportamento produtivo e qualitativo das plantas forrageiras, bem como das condições edafoclimáticas locais, onde são necessárias pesquisas específicas, que demonstrem a realidade da produção, bem como a qualidade da forragem. Com base no exposto, objetivou-se estudar doses de N: 0, 50, 100, 150 e 200 $\mathrm{kg} \mathrm{ha}^{-1}$, por corte e fontes; nitrato de amônio e ureia, avaliando-se o acúmulo de matéria seca, bem como de nitrogênio, fósforo e potássio do capim-mombaça (Panicum maximum cv. Mombaça).

\section{Material e Métodos}

O experimento foi conduzido entre os anos de 2012 a 2014 na Fazenda de Ensino, Pesquisa e Extensão da Universidade Estadual Paulista, Campus de Ilha Solteira - SP, localizada à margem esquerda do Rio Paraná, com coordenadas $20^{\circ} 21^{\prime}$ latitude sul e $51^{\circ} 22^{\prime}$ longitude oeste, a altitude de $326 \mathrm{~m}$, em área antes ocupada por pastagem de Panicum maximum subpastejada desde 2006. O solo foi classificado como Argissolo Vermelho Escuro eutrófico, de textura arenosa, segundo a Embrapa (2013). A precipitação total durante o tempo de experimento foi de $1820 \mathrm{~mm}$, com umidade relativa do ar média de $70 \%$, e temperatura média de $25,3{ }^{\circ} \mathrm{C}$, oscilando na temperatura mínima e máxima médias de 19,8 a $32,2^{\circ} \mathrm{C}$. O tipo climático é Aw, segundo Köppen caracterizado como tropical úmido com estação chuvosa no verão e seca no inverno. Na Figura 1 encontram-se os dados climáticos médios referentes a cada corte efetuado.

Realizou-se a coleta da amostra do solo na profundidade de $0-20 \mathrm{~cm}$, anteriormente ao rebaixamento inicial do capim, em 2012 para determinar as características químicas do solo, apresentando os seguintes resultados: $\mathrm{P}$ (resina) $=13 \mathrm{mg} \mathrm{dm}{ }^{-3}, \mathrm{pH} \mathrm{CaCl}_{2}$ $=5,2 ; \mathrm{K}, \mathrm{Ca}, \mathrm{Mg}, \mathrm{H}+\mathrm{Al}, \mathrm{SB}, \mathrm{CTC}=2,2,35,0,7,0,16,0$, 27,0 e $48,0 \mathrm{mmol}_{\mathrm{c}} \mathrm{dm}^{-3}$, respectivamente, M.O. $=25 \mathrm{~g}$ $\mathrm{dm}^{-3}$ e V $\%=56$. 


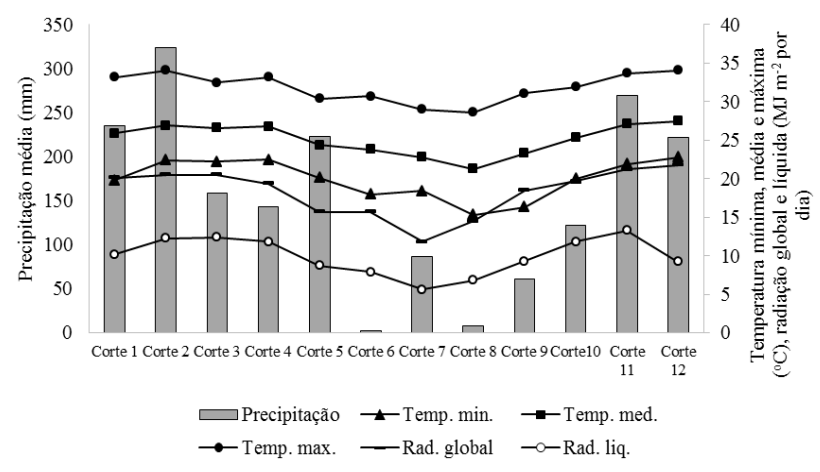

Figura 1. Dados climáticos obtidos junto à estação meteorológica situada na Fazenda de Ensino, Pesquisa e Extensão da FE/UNESP. Períodos de dezembro de 2012 a janeiro de 2014.

$\mathrm{O}$ delineamento experimental utilizado foi em blocos casualizados com dez tratamentos e quatro repetições, com duas fontes de N: a ureia $(45 \%$ de $\mathrm{N})$, por ser o fertilizante nitrogenado mais utilizado e com o $\mathrm{N}$ passível de ser volatilizado e o nitrato de amônio ( $32 \%$ de $\mathrm{N}$ ), como fonte comparativa. Foram utilizadas cinco doses de $\mathrm{N}$ para cada fonte $(0,50,100,150$ e 200 $\mathrm{kg} \mathrm{ha}^{-1}$ ), após cada corte no esquema fatorial 2 × 5 (duas fontes e cinco doses de $\mathrm{N}$ ). Cada parcela teve área de $6,0 \mathrm{~m}^{2}(3 \times 2 \mathrm{~m})$, com $2 \mathrm{~m}$ de espaçamento entre elas.

$\mathrm{A}$ área foi dessecada com a mistura dos herbicidas glyphosate (1800 $\mathrm{g} \mathrm{ha}^{-1}$ e.a. - equivalente ácido) e 2,4-D $\left(670 \mathrm{~g} \mathrm{ha}^{-1}\right.$ i.a. ingrediente ativo) e posteriormente preparada com uma aração e duas gradagens; o capimmombaça foi semeado a lanço no dia 10 de janeiro de 2006. Na implantação da gramínea, o solo foi corrigido quanto à fertilidade aplicando-se $20 \mathrm{~kg} \mathrm{ha}^{-1} \mathrm{de} \mathrm{N}$ (ureia). $\mathrm{O}$ fósforo $(\mathrm{P})$ e o potássio $(\mathrm{K})$ foram baseados em doses teóricas para se atingir valores de $\mathrm{P}$ de $30 \mathrm{mg} \mathrm{dm}^{-3} \mathrm{e} \mathrm{K}$ a $5 \%$ da CTC, usando como fontes o superfosfato simples ( $18 \%$ de $\left.\mathrm{P}_{2} \mathrm{O}_{5}\right)$ e o cloreto de potássio $\left(60 \%\right.$ de $\left.\mathrm{K}_{2} \mathrm{O}\right)$.

$\mathrm{O}$ corte de rebaixamento para início da adubação inicial e posterior crescimento para os cortes de avaliação foi feito no dia 12/07/2012 e os demais cortes foram realizados de dezembro de 2012 a janeiro de 2014. As datas dos cortes foram: 16/12/2012; $15 / 01 / 2013 ; \quad 16 / 02 / 2013 ; \quad 21 / 03 / 2013 ; \quad 20 / 04 / 2013$; 25/05/2013; 28/06/2013; 03/08/2013; 26/09/2013; 01/11/2013; 11/12/2013 e 18/01/2014. Devido à quantidade do número de cortes e para melhor interpretação dos dados, os cortes foram divididos em períodos do ano: período seco $(20 / 04 / 2013 ; 25 / 05 / 2013$; 28/06/2013; 03/08/2013; 26/09/2013 e 01/11/2013) e período chuvoso $(11 / 12 / 2013 ; 18 / 01 / 2014 ; 16 / 12 / 2012$; 15/01/2013; 16/02/2013 e 21/03/2013).

A coleta da parte aérea do capim-mombaça foi realizada manualmente com um cutelo e auxílio de um quadro de ferro delimitando a área de coleta em cada parcela (delimitando-se a área de $0,5 \mathrm{~m}^{2}$ - quadrado metálico de $1 \times 0,5 \mathrm{~m}$ ), cortando o capim a $25 \mathrm{~cm}$ de altura do solo, no centro das parcelas. A tomada de decisão do momento do corte baseou-se na altura do capim, variando em, aproximadamente 90 a $100 \mathrm{~cm}$ de altura, ou seja, sempre que o capim-mombaça atingia altura entre 90 a $100 \mathrm{~cm}$, eram efetuadas as coletas. De maneira geral, ocorreu praticamente um corte por mês, com exceção do primeiro corte, devido à falta de chuva no período e pouco crescimento das plantas.

A forragem colhida (massa verde total) foi pesada, uma alíquota de matéria verde foi ensacada em sacos de papel e também pesada (massa verde ensacada) e posteriormente, seca em estufa de circulação de ar forçada, com temperatura média de $65{ }^{\circ} \mathrm{C}$, por 72 horas. Em seguida, as amostras foram pesadas (massa seca ensacada) para o cálculo de massa seca total e quantificação da MS produzida na área representativa, e moídas em moinho tipo Willey equipado com peneira com crivos de $1 \mathrm{~mm}$. O restante do capim das parcelas foi cortado (ceifado) com roçadeira mecânica e removido das parcelas. Após cada corte as doses de $\mathrm{N}$ foram aplicadas a lanço sobre o capim de cada parcela, segundo os tratamentos. O acúmulo de matéria seca do capim-mombaça foi calculado com base na quantidade de matéria seca total na área representativa de cada parcela, que dividida pelo período entre cada corte propiciou o acúmulo de MS diário, em $\mathrm{kg} \mathrm{ha}^{-1}$ dia.

Foram realizadas as análises químicas foliares para determinação dos teores de N, P e K. Para a determinação do nitrogênio total (NT) a digestão foi a sulfúrica e o método analítico o semi micro-Kjeldahl; o $\mathrm{P}$ foi determinado por colorimetria do metavanado e o $\mathrm{K}$ por espectrofotometria de chama de emissão (Malavolta et al., 1997).

Para os cálculos de acúmulo de nitrogênio, fósforo e potássio foram multiplicados os respectivos teores nutricionais de parte aérea $\left(\mathrm{g} \mathrm{kg}^{-1}\right)$ pela MS $\left(\mathrm{kg} \mathrm{ha}^{-1}\right)$, dividindo o resultado obtido por 1000 para obtenção dos valores de acúmulo nutricional $\mathrm{em} \mathrm{kg} \mathrm{ha}^{-1}$.

Os dados foram submetidos à análise de variância (teste F). Para as fontes de $\mathrm{N}$ foi utilizado o teste de Tukey para a comparação das médias, e para as doses de $\mathrm{N}$ foi realizada análise de regressão. As análises estatísticas foram realizadas com o emprego do programa Sisvar (Ferreira, 2011).

\section{Resultados e Discussão}

Com relação ao acúmulo de nitrogênio na parte aérea (Tabela 1), a interação foi significativa, onde para o período seco houve ajuste a função linear crescente para a ureia, e ajuste a função quadrática para o nitrato de amônio (N.A.), com ponto de máxima na dose de $774 \mathrm{~kg} \mathrm{ha}^{-1}$, propiciando $251,7 \mathrm{~kg} \mathrm{ha}^{-1}$ de acúmulo de $\mathrm{N}$ (Figura 2A). $\mathrm{O}$ aumento no acúmulo de $\mathrm{N}$ da ureia $\mathrm{e}$ 
N.A. da dose testemunha até a dose de $1200 \mathrm{~kg} \mathrm{ha}^{-1}$ foi de, respectivamente, 54,7 e $119,9 \mathrm{~kg} \mathrm{ha}^{-1}$, equivalente ao aumento de 28 e $88 \%$.

Tal resultado obtido com o N.A. é interessante uma vez que ao possibilitar a definição da dose de $\mathrm{N}$ a ser aplicada com resposta positiva no acúmulo de $\mathrm{N}$, sendo possível diminuir a quantidade de fertilizante utilizada, aliando economia com suprimento de nitrogênio adequado para a cultura, principalmente no período seco, que apresenta menor produtividade e rendimento animal. Para o período chuvoso, os dados tanto da ureia quanto do N.A. se ajustaram a função linear crescente em função das doses de nitrogênio (Figura 2B). Fica clara a diferença de acúmulo de $\mathrm{N}$ em função dos períodos, uma vez que o período chuvoso favorece melhores condições para o crescimento da cultura, o que influenciou na resposta as elevadas doses de $\mathrm{N}$ utilizadas, com resposta positiva à aplicação de $200 \mathrm{~kg}$ $\mathrm{ha}^{-1}$ por corte, equivalente a $1200 \mathrm{~kg} \mathrm{ha}^{-1}$ no decorrer do período. Vale ressaltar que o capim-mombaça apresenta também elevada resposta à adubação nitrogenada e crescimento agressivo em parte aérea (GALINDO et al., 2017), o que explicaria também o ajuste linear no período chuvoso. $\mathrm{O}$ incremento do acúmulo de $\mathrm{N}$ da ureia e N.A. da dose testemunha até a dose de $1200 \mathrm{~kg}$ $\mathrm{ha}^{-1}$ de $\mathrm{N}$ foi de 194,7 e $279,5 \mathrm{~kg} \mathrm{ha}^{-1}$ respectivamente, um aumento de 55 e $82 \%$.

Tais resultados eram esperados, uma vez que ao se aumentar as doses de nitrogênio a tendência é de se aumentar também a disponibilidade de nitrogênio à gramínea forrageira, culminando no aumento da absorção e nos teores de $\mathrm{N}$ em parte aérea, aumentando consequentemente o acúmulo deste nutriente em parte aérea. Com base nos resultados obtidos, verificou-se que o acúmulo de nutrientes em parte aérea do capimmombaça foi elevado, principalmente no período chuvoso (Tabela 1). Oliveira et al. (2005) encontraram acúmulo e posterior exportação de $326 \mathrm{~kg} \mathrm{ha}^{-1}$ por ano de $\mathrm{N}$ durante a recuperação de uma pastagem de capimmarandu.

Também Costa et al. (2008), trabalhando com as doses de $\mathrm{N} 0,25,50$ e $100 \mathrm{mg} \mathrm{dm}^{-3}$ em casa de vegetação, verificaram que a extração de $\mathrm{N}$ apresentou ajuste linear com o incremento das doses de $\mathrm{N}$, onde os efeitos da maior dose de $\mathrm{N}$ sobre extração de $\mathrm{N}$ em relação à testemunha propiciaram um aumento de $49,8 \%$. Segundo os autores, este acentuado incremento da extração de $\mathrm{N}$ em função das doses de $\mathrm{N}$ ocorreu também devido à absorção de $\mathrm{N}$ com o aumento da dose fornecida e ao aumento da produção de MS em função da atuação do nutriente na produção.

Resultado semelhante foi observado por Primavesi et al. (2006), onde os autores obtiveram aumento de cerca de $75 \%$ em relação à testemunha, no acúmulo de $\mathrm{N}$ na braquiária, quando suprida com $200 \mathrm{~kg} \mathrm{~N} \mathrm{ha}^{-1}$. Diversos autores obtiveram resultados positivos nos teores foliares e acúmulo de $\mathrm{N}$ com o incremento das doses de N, como Magalhães et al. (2011), estudando adubação nitrogenada em capim-braquiária (Brachiaria decumbens) nas doses 0, 100, 200 e 300 $\mathrm{kg} \mathrm{ha}^{-1}$ por ano e Freitas et al. (2007) no capimmombaça nas doses 70, 140, 210 e $280 \mathrm{~kg} \mathrm{ha}^{-1}$ por ano.

Diferentemente, Volpe et al. (2008), utilizando as doses de $0,100,200$ e $300 \mathrm{~kg} \mathrm{ha}^{-1}$ na implantação do capim-massai, não verificaram resposta da adubação nitrogenada na concentração de $\mathrm{N}$ em parte aérea. Segundo os autores a falta de resposta ao $\mathrm{N}$ pode ter sido causada pelo suprimento deste nutriente pelo solo por meio da mineralização da MO decorrente do preparo do solo, da calagem e adubação e/ou pela baixa eficiência da adubação nas condições climáticas no período experimental.

Tabela 1. Médias, coeficientes de variação (C.V.), teste de Tukey e equações de regressão relacionados ao acúmulo de nitrogênio, fósforo e potássio em parte aérea nos períodos seco e chuvoso do capim-mombaça na região de Ilha Solteira -SP.

\begin{tabular}{|c|c|c|c|c|c|c|c|c|}
\hline & Seco & Chuvoso & Seco & Chuvoso & Seco & Chuvoso & Seco & Chuvoso \\
\hline $\begin{array}{c}\text { Doses de N } \\
\left(\mathrm{kg} \mathrm{ha}^{-1}\right)\end{array}$ & \multicolumn{2}{|c|}{$\mathrm{N}\left(\mathrm{kg} \mathrm{ha}^{-1}\right)$} & \multicolumn{2}{|c|}{$\mathrm{P}\left(\mathrm{kg} \mathrm{ha}^{-1}\right)$} & \multicolumn{2}{|c|}{$\mathrm{K}\left(\mathrm{kg} \mathrm{ha}^{-1}\right)$} & \multicolumn{2}{|c|}{ MS (kg ha ${ }^{-1}$ por dia) } \\
\hline$\overline{0}$ & $167,49^{* *}$ & $348,81^{* *}$ & $18,49^{\mathrm{ns}}$ & $55,25^{\mathrm{ns}}$ & $233,67^{*}$ & $590,78^{* *}$ & $45,84^{* *}$ & $102,68^{* * *}$ \\
\hline 300 & 198,28 & 372,45 & 17,67 & 45,32 & 242,74 & 620,92 & 50,61 & 110,59 \\
\hline 600 & 240,96 & 483,49 & 22,68 & 64,83 & 284,05 & 744,91 & 55,30 & 117,65 \\
\hline 900 & 264,86 & 564,63 & 22,99 & 58,15 & 306,97 & 796,78 & 58,71 & 132,54 \\
\hline 1200 & 254,80 & 585,90 & 20,62 & 56,79 & 290,56 & 752,75 & 57,58 & 127,59 \\
\hline Média Geral & 225,28 & 471,06 & 20,49 & 56,07 & 271,60 & 701,22 & 53,61 & 118,21 \\
\hline C.V. (\%) & 14,01 & 13,63 & 14,06 & 12,59 & 17,67 & 11,64 & 12,87 & 11,58 \\
\hline \multicolumn{9}{|l|}{ Fontes de $\mathrm{N}$} \\
\hline Ureia & 225,78 & 451,07 & $20,57 \mathrm{a}$ & $52,48 \mathrm{~b}$ & 278,70 & 688,03 & 53,58 & 116,57 \\
\hline Nitrato de Amônio & 224,77 & 491,04 & $20,41 \mathrm{a}$ & $59,65 \mathrm{a}$ & 264,50 & 714,42 & 53,63 & 119,85 \\
\hline D.M.S. $(5 \%)$ & 31,94 & 64,95 & 2,91 & 7,14 & 48,54 & 82,55 & 4,48 & 8,88 \\
\hline
\end{tabular}

Médias seguidas de mesma letra na coluna não diferem pelo teste de Tukey, a $5 \%$ de probabilidade. 
A

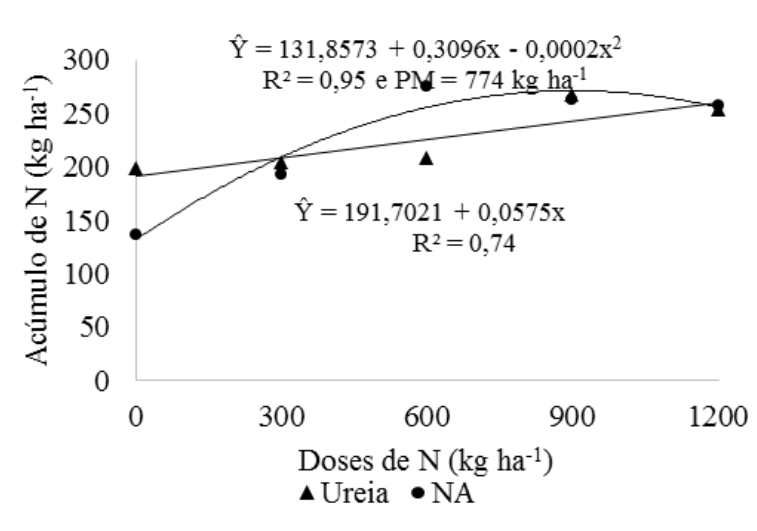

$\mathrm{C}$

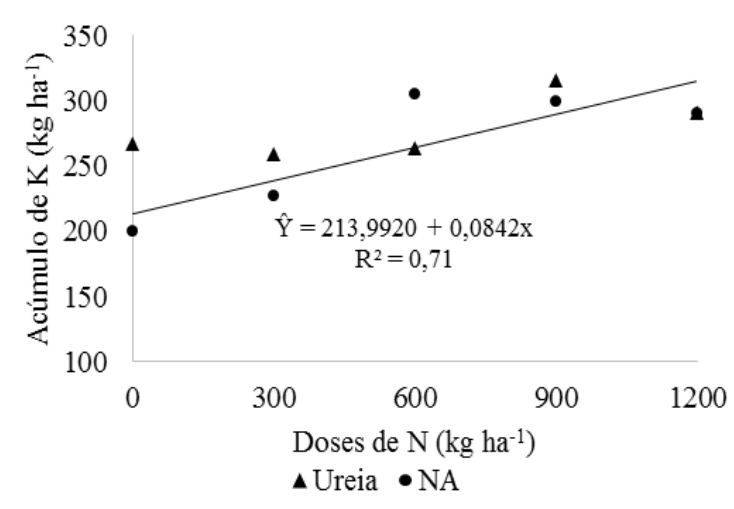

$\mathrm{E}$

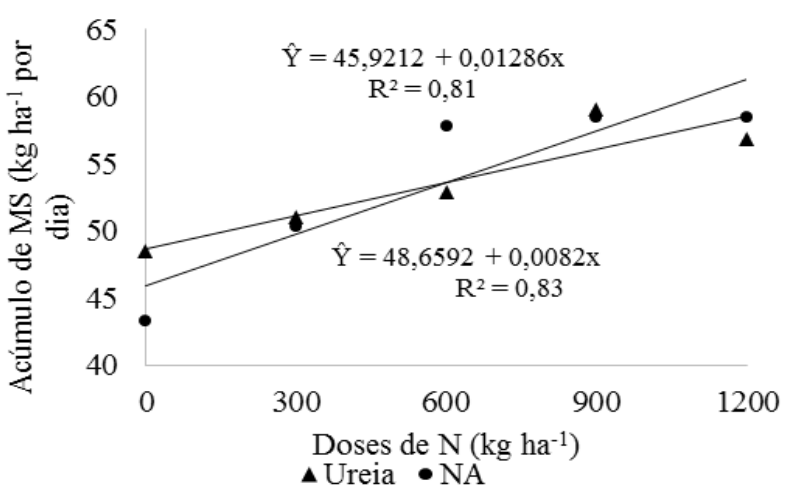

B

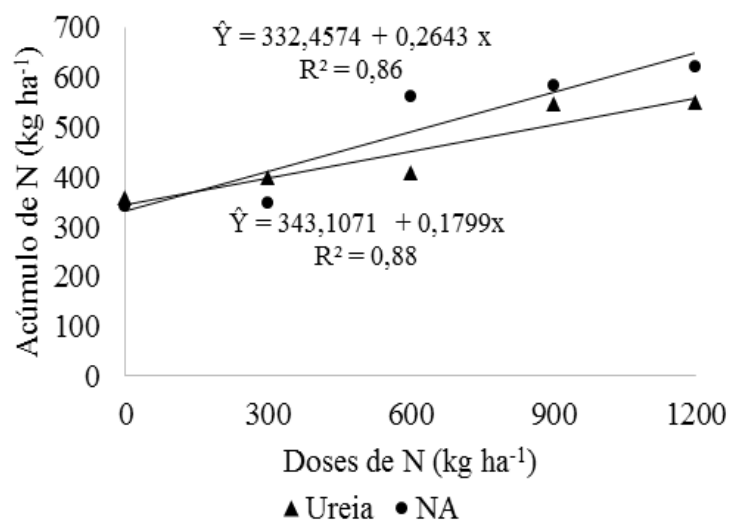

$\mathrm{D}$

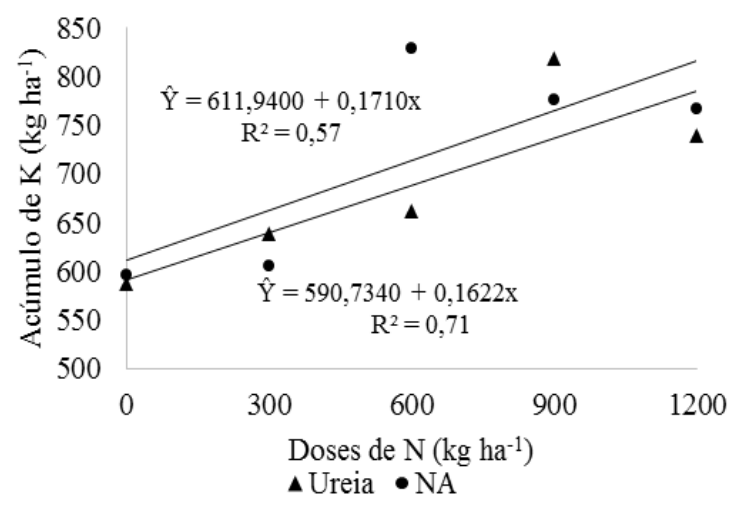

F

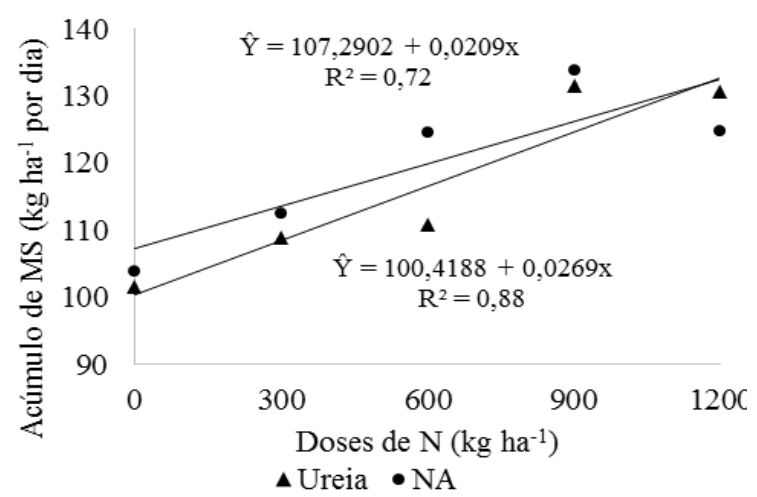

Figura 2. Interação entre doses e fontes no acúmulo de nitrogênio em parte aérea no capim-mombaça, do período seco (A), e período chuvoso (B), interação entre doses e fontes no acúmulo de potássio em parte aérea no capim-mombaça, do período seco (C) e chuvoso (D), interação entre doses e fontes no acúmulo de matéria seca diária em parte aérea no capim-mombaça, do período seco (E) e chuvoso (F). Ilha Solteira - SP, 2012/2014.

Neste contexto, Oliveira et al. (2005) ponderam que a indicação de pontos de equilíbrio para diferentes níveis de produção de matéria seca de forragem, por meio de curvas de resposta ao nitrogênio ao longo dos anos, seria de grande valia para o manejo da fertilização nitrogenada em pastagens, principalmente quando o sistema se encontra em recuperação, validando desta maneira a importância de estudos com resposta à adubação nitrogenada em diferentes períodos, como no presente trabalho.

No que se refere ao acúmulo de fósforo na parte aérea do capim-mombaça, não houve influência das doses de $\mathrm{N}$ e das fontes no período seco. Contudo, no período chuvoso o N.A. propiciou maior acúmulo de $\mathrm{P}$ comparativamente à ureia (Tabela 1). Concordando com os resultados obtidos, Volpe et al. (2008) não verificaram resposta à adubação nitrogenada na 
concentração de $\mathrm{P}$ na parte aérea, assim como Mistura et al. (2006), trabalhando com as doses 100, 200, 300 e $400 \mathrm{~kg} \mathrm{ha}^{-1}$ de $\mathrm{N}$ na fonte ureia não verificaram influência nos teores de $\mathrm{P}$ do capim-elefante pela adubação nitrogenada.

Contudo, Costa et al. (2008) relataram que a concentração de $\mathrm{P}$ no capim-xaraés apresentou uma curva quadrática com o aumento das doses de $\mathrm{N}$ e $\mathrm{K}$ e o efeito individual da maior dose de $\mathrm{N}$ foi responsável por um aumento de 42,6\% na extração de $\mathrm{P}$, contudo o efeito principal responsável pelo aumento da extração de $\mathrm{P}$ com relação à testemunha foi a interação entre a adubação nitrogenada, fosfatada e potássica, mostrando aumento de 97,4\%. Diferentemente, Costa et al. (2009) concluiram que o incremento na adubação nitrogenada reduz a absorção de P. Primavesi et al. (2006), trabalhando com doses e fontes de nitrogênio no capimmarandu, verificaram que as concentrações de fósforo não variaram com doses de $\mathrm{N}$ na forma de N.A. e reduziram na forma de ureia.

Para o acúmulo de potássio na parte aérea, a interação entre doses e fontes foi significativa para o acúmulo de potássio, onde para o período seco, o N.A. foi influenciado positivamente com o aumento das doses, com ajuste a função linear crescente (Figura 2C). Para o período chuvoso, ambas as fontes foram influenciadas positivamente pelo aumento das doses, com ajuste a função linear crescente (Figura 2D).

No período seco, o incremento do acúmulo de $\mathrm{K}$ da ureia e N.A. da dose testemunha até a dose de $1200 \mathrm{~kg}$ $\mathrm{ha}^{-1}$ foi de, respectivamente às fontes de $\mathrm{N}, 23,46 \mathrm{e}$ $90,31 \mathrm{~kg} \mathrm{ha}^{-1}$, equivalente ao aumento de 8,8 e 45,1\%. Para o período chuvoso, o incremento do acúmulo de MS da ureia e N.A. da dose testemunha até a dose de $1200 \mathrm{~kg} \mathrm{ha}^{-1}$ foi de, respectivamente 153,0 e $170,9 \mathrm{~kg}$ $\mathrm{ha}^{-1}$ dia, um aumento de 26,1 e $28,7 \%$.

O N é um componente importante das proteínas, além de maximizar o rendimento da matéria seca de gramíneas forrageiras, sendo o principal nutriente para a manutenção de sua produtividade (Dupas et al., 2016). Quando aplicado, é assimilado pela planta e associado às cadeias de carbono promove aumento dos constituintes celulares e consequente aumento do vigor do rebrote e da produção total de matéria seca verde das plantas sob condições climáticas favoráveis (Galindo et al., 2017), além de maior absorção de nutrientes, como verificado no presente trabalho.

Uma possível explicação do aumento do acúmulo de $\mathrm{K}$ na parte aérea é devido ao fato de, possivelmente, ao aumentar a dose e consequentemente o acúmulo de $\mathrm{N}$ na forrageira, houve maior desenvolvimento do sistema radicular e consequente aumento na parte aérea, aumentando a absorção de K. Vale ressaltar que um sistema radicular melhor desenvolvido consegue explorar maior volume de solo, com tendência de absorver maior quantidade de nutrientes apresentando reflexo positivo no desenvolvimento da cultura. $\mathrm{O}$ sistema radicular das gramíneas forrageiras é conhecido pelo crescimento agressivo e desenvolvimento em profundidade, fato este que pode ter auxiliado na absorção de $\mathrm{K}$ lixiviado para as camadas subsuperficiais.

Outra explicação possível está relacionada ao chamado "consumo de luxo", onde as plantas absorvem quantidade acima da sua necessidade metabólica, que é acumulada em organelas da célula vegetal, como nos cloroplastos, nas mitocôndrias e, especialmente, nos vacúolos (Gommers et al., 2005). Segundo Rosolem et al. (2012) tal inferência deve-se ao fato de que o K absorvido permanecer a maior parte do tempo no tecido vegetal, vivo ou morto, protegido de perdas por erosão e lixiviação e que, portanto, espécies com elevada capacidade de extrair $\mathrm{K}$ do solo e, ou, capazes de explorar camadas profundas do solo como as gramíneas forrageiras, em especial o capim-mombaça, são de extrema importância para a sustentabilidade dos sistemas de produção agrícola, por maximizar o aproveitamento de $\mathrm{K}$ e manter a fertilidade do solo, evidenciando o potencial das gramíneas forrageiras como culturas cicladoras de nutrientes.

Resultados semelhantes foram verificados por Primavesi et al. (2006), trabalhando com doses de N: 50,100 e $200 \mathrm{~kg} \mathrm{ha}^{-1}$ por corte, nas formas de ureia e de N.A., que verificaram aumento das concentrações de $\mathrm{K}$ com doses de $\mathrm{N}$, indicando potencial de extração de $\mathrm{K}$ do solo pelas gramíneas forrageiras, como verificado neste trabalho e também concordando com Costa et al. (2008), que obtiveram ajuste quadrático na extração de $\mathrm{K}$ com o aumento das doses de $\mathrm{N}$ e $\mathrm{K}$ aplicadas, considerando apenas o efeito do $\mathrm{N}$; aumento em relação à testemunha de $31 \%$.

De maneira semelhante, Costa et al. (2009), trabalhando com as doses $0,100,200$ e $300 \mathrm{~kg} \mathrm{ha}^{-1}$, por ano, nas fontes ureia e sulfato e amônio, relataram efeito significativo para doses de $\mathrm{N}$ influenciando na concentração de potássio em três anos avaliados, onde a concentração de $\mathrm{K}$ na parte aérea do capim-marandu aumentou linearmente com o acréscimo das doses de $\mathrm{N}$. $\mathrm{O} \mathrm{K}$ aumenta a eficiência de uso do $\mathrm{N}$; com teores baixos de $\mathrm{K}$ nas plantas os compostos de $\mathrm{N}$ solúvel acumulam-se.

Diferentemente, Mistura et al. (2006), estudando doses de $\mathrm{N}+\mathrm{K}$, não verificaram diferença nos teores de $\mathrm{K}$ nas lâminas foliares do capim-elefante. Segundo os autores a ausência de efeito significativo de adubação sobre os teores de $\mathrm{K}$ na planta pode ser explicada pelos elevados teores de nutrientes disponíveis no solo no início do estudo.

A disponibilidade do $\mathrm{N}$ e do $\mathrm{K}$ e a adequada proporção entre eles no solo são fatores importantes nos 
processos de crescimento e desenvolvimento das plantas (Viana; Kiehl, 2010). O metabolismo de nitrogênio nas plantas requer adequadas quantidades de potássio no citoplasma (Xu et al., 2002), sendo importante para a produção de aminoácidos e produtividade das culturas (Viana; Kiehl, 2010). Estudos recentes tem verificado que o potássio está envolvido na fase final do metabolismo do nitrogênio (Marschner, 1995), entretanto, alguns trabalhos relatam que o potássio está envolvido no início dos processos metabólicos do nitrogênio, como incorporação do nitrogênio mineral e especialmente na redutase do nitrato (Ruan et al., 1999).

A redutase do nitrato é considerada uma enzimachave na regulação do metabolismo do nitrogênio. Por causa desse papel regulador, a atividade da redutase do nitrato poderia estar relacionada, indiretamente, com a produtividade das culturas, pois se pode supor que plantas com alta atividade da redutase do nitrato teriam maior capacidade de assimilar o nitrato disponível e, em consequência, maior capacidade em responder à adubação nitrogenada (Viana; Kiehl, 2010), explicando também o aumento em acúmulo de MS do capimmombaça (Tabela 1).

Com relação ao acúmulo de matéria seca, a interação entre doses e fontes foi significativa; o aumento das doses influenciou ambas as fontes com ajuste a função linear crescente para a ureia e para o N.A. (Figura 2E e Figura 2F). No período seco, o incremento do acúmulo de MS da ureia e N.A. da dose testemunha até a dose de $1200 \mathrm{~kg} \mathrm{ha}^{-1}$ foi de 8,3 e $15,18 \mathrm{~kg} \mathrm{ha}^{-1}$ dia, respectivamente, equivalente ao aumento de 17,1 e $35,1 \%$. Para o período chuvoso, o incremento do acúmulo de MS da ureia e N.A. da dose testemunha até a dose de $1200 \mathrm{~kg} \mathrm{ha}^{-1}$ foi de 29,04 e 20,8 $\mathrm{kg} \mathrm{ha}^{-1}$ dia, respectivamente, um aumento de 28,6 e 20,0\%.

$\mathrm{O}$ aumento do acúmulo de nitrogênio e potássio na parte aérea com o aumento das doses de N (Tabela 1) evidencia maior absorção destes nutrientes, o que possivelmente contribuiu com o aumento da massa seca, uma vez que o estado nutricional da cultura influi diretamente na produtividade de matéria seca, principalmente se tratando dos nutrientes $\mathrm{N}$ e $\mathrm{K}$, os quais, de maneira geral, são exigidos em maior quantidade pelas gramíneas forrageiras. $\mathrm{O}$ aumento no acúmulo de matéria seca, no período seco, da testemunha para a maior dose aplicada (1200 $\left.\mathrm{kg} \mathrm{ha}^{-1}\right)$ foi de $11,74 \mathrm{~kg} \mathrm{ha}^{-1} \mathrm{dia}$, um aumento equivalente a $25,6 \%$. Para o período chuvoso, o aumento foi de 24,91 $\mathrm{kg} \mathrm{ha}^{-1}$ dia, equivalente a $24,3 \%$ de aumento.

Martuscello et al. (2006) e Magalhães et al. (2011) obtiveram incremento no acúmulo de MS com o aumento das doses de $\mathrm{N}$, corroborando com os dados obtidos neste trabalho. De maneira semelhante, Fagundes et al. (2005) verificaram que o suprimento de $\mathrm{N}$ no solo normalmente não atende à demanda das gramíneas, porém, quando há adubação nitrogenada, são observadas grandes alterações na taxa de acúmulo de MS da forragem ao longo dos períodos do ano.

Resultados semelhantes foram obtidos por Rodrigues et al. (2008) e podem estar relacionados à necessidade de recuperação das estruturas da planta forrageira, como a coroa e o sistema radicular, para que a mesma possa expressar seu potencial de resposta em produtividade e também a melhor eficiência do uso do nitrogênio pela pastagem. Lugão et al. (2003) também verificaram aumento das taxas de acúmulo de MS com o aumento das doses de $\mathrm{N}$ e concluíram que para alcançar o potencial máximo das gramíneas forrageiras, a adubação nitrogenada é fundamental e de extrema importância.

Altas taxas de acumulo de MS, durante o período das águas, com adubação nitrogenada também foram observadas por Santos et al. (1999) em capim-tanzânia (114 $\mathrm{kg} \mathrm{ha}^{-1}$ por dia) e em capim-mombaça $\left(157 \mathrm{~kg} \mathrm{ha}^{-1}\right.$ por dia), com 400kg de $\mathrm{N} \mathrm{ha}^{-1}$. Favoretto et al. (1988), testando doses de nitrogênio $\left(0,50\right.$ e $\left.100 \mathrm{~kg} \mathrm{ha}^{-1}\right)$ em capim-colonião, verificaram que a taxa de crescimento aumentou de 68 para $84 \mathrm{~kg}$ de $\mathrm{MS} \mathrm{ha}^{-1}$ por dia quando a dose de $\mathrm{N}$ variou de 50 para $100 \mathrm{~kg} \mathrm{ha}^{-1}$, respectivamente.

Com base nos resultados obtidos fica evidente a importância da adubação nitrogenada em pastagens, independentemente do período em questão, visando uma produtividade de matéria seca satisfatória e com teores adequados de nutrientes.

\section{Conclusões}

Doses de $\mathrm{N}$ na forma de ureia ou nitrato de amônio incrementam o acúmulo de N, Ke MS em pastagens de capimmombaça.

As fontes de $\mathrm{N}$ não influenciaram no acúmulo de $\mathrm{N}, \mathrm{P}, \mathrm{K}$ e MS. Portanto, recomenda-se o uso da ureia, por ser o fertilizante de maior concentração de $\mathrm{N}$ e de menor relação custo por unidade de nutriente, na dose de $100 \mathrm{~kg} \mathrm{ha}^{-1}$, propiciando aumento no acúmulo de nutrientes, bem como na matéria seca, além da manutenção do capim-mombaça.

\section{Referências Bibliográficas}

Barth Neto, A.; Boleta, V.S.; Pancera Júnior, E.J.; Almeida, G.M.; Canto, M.W.; Gasparino, E.; Baltazar, L.F. 2011. Nitrogênio e época de colheita nos componentes da produtividade de forragem e sementes de capim-mombaça. Pesquisa Agropecuária Brasileira, Brasília, 45, 11, pp. 13121320.

Benett, C.C.S.; Buzetti, S.; Silva, K.S.; Bergamaschine, A.F.; Fabricio, J.A. 2008. Produtividade e composição bromatológica do capimmarandu a fontes e doses de nitrogênio. Ciência e Agrotecnologia, Lavras, 32, 5, pp. 1629-1636. 
Costa, K.A.P.; Faquin, V.; Oliveira, I.P. 2009. Doses e fontes de nitrogênio na nutrição mineral do capim-marandu. Ciência Animal Brasileira, Goiânia, 10, 1, pp. 115-123.

Costa, K.A.P.; Araujo, J.L.; Faquin, V.; Oliveira, I.O.; Figueiredo, F.C.; Gomes, K.W. 2008. Extração de macronutrientes na fitomassa do capim-xaraés em função de doses de nitrogênio e potássio. Ciência Rural, Santa Maria, 38, 4, pp. 1162-1166.

Dupas, E.; Buzetti, S.; Rabêlo, F.H.S.; Sarto, A.L.; Cheng, N.C.; Teixeira Filho, M.C.M.; Galindo, F.S.; Dinalli, R.P.; Gazola, R.N. 2016. Nitrogen recovery, use efficiency, dry matter yield, and chemical composition of palisade grass fertilized with nitrogen sources in the Cerrado biome. Australian Journal of Crop Science, 10, 9, pp. 1330-1338.

EMBRAPA. EMPRESA BRASILEIRA DE PESQUISA AGROPECUÁRIA. 2013. Sistema Brasileiro de Classificação de Solos. 3. ed. Brasília-DF: Centro Nacional de Pesquisa de Solos -Embrapa, 353 p.

Euclides, V.P.B.; Macedo, M.C.M.; Zimmer, A.H.; Medeiros, R.N.; Oliveira, M.P. 2007. Características do pasto de capimtanzânia adubado com nitrogênio no final do verão. Pesquisa Agropecuária Brasileira, Brasília, 42, 8, pp. 1189-1198.

Fagundes, J.L.; Fonseca, D.M.; Gomide, J.A.; Nascimento Junior, D.; Vitor, C.M.T.; Morais, R.V.; Mistura, C.; Reis, G.C.; Martuscello, J.A. 2005. Acúmulo de forragem em pastos de Brachiaria decumbens adubados com nitrogênio. Pesquisa Agropecuária Brasileira, Brasília, 40, 4, pp. 397-403.

Favoretto, V.; Rodrigues, L.R.A.; Tupinambá, C.F. Estudo do nitrogênio na produção e composição bromatológica do capim-colonião e seus aspectos econômicos. Científica, Jaboticabal, 16, 1, pp. 71-78.

Fernandes, J.C.; Buzetti, S.; Dupas, E.; Teixeira Filho, M.C.M.; Andreotti, M. 2015. Sources and rates of nitrogen fertilizer used in Mombasa guineagrass in the Brazilian Cerrado region. African Journal of Agricultural Research, Ebene, 10, 19, pp. 2076-2082.

FERREIRA, D.F. 2011. Sisvar: a computer statistical analysis system. Ciência e Agrotecnologia, Lavras, 35, 6, pp. 10391042.

Freitas, K.R.; Rosa, B.; Ruggiero, J.A.; Nascimento, J.L.; Heinemam, A.B.; Macedo, R.F.; Naves, M.A.T.; Oliveira, I.P. 2007. Avaliação da composição químico - bromatológica do capim-mombaça (Panicum maximum jacq.) submetido a diferentes doses de nitrogênio. Bioscience Journal, Uberlândia, 23, 3, pp. 1-10.

Galindo, F.S.; Buzetti, S.; Teixeira Filho, M.C.M.; Dupas, E.; Ludkiewicz, M.G.Z. 2017. Application of different nitrogen doses to increase nitrogen efficiency in Mombasa guinegrass (Panicum maximum cv. mombasa) at dry and rainy seasons. Australian Journal of Crop Science, 11, 12, pp. 1657-1664.

Gommers, A.; Thiry, Y.; Delvaux, B. 2005. Rhizospheric mobilization and plant uptake of radiocesium from weathered soils: I. Influence of potassium depletion. Journal of Environmental Quality, Madison, 34, 6, pp. 2167-2173.

Lugão, S.M.B.; Rodrigues, L.R.A.; Abrahão, J.J.S.; Malheiros, E.B.; Morais, A. 2003. Acúmulo de Forragem e eficiência de utilização do nitrogênio em pastagem de Panicum maximum Jacq. (Acesso BRA-006998) adubadas com nitrogênio. Acta Scientiarum. Animal Sciences, Maringá, 25, 2, pp. 371-379.

Magalhães, A.F.; Pires, A.J.V.; Carvalho, G.G.P.; Sousa, R.S.; Silva, F.F.; Bonomo, P.; Veloso, C.M.; Magalhães, D.M.A.; Pereira, J.M. 2011. Composição bromatológica e concentrações de nutrientes do capim-braquiária adubado com nitrogênio e fósforo. Revista Brasileira de Saúde e Produção Animal, Salvador, 12, 4, pp. 893-907.

Malavolta, E.; Vitti, G.C.; Oliveira, S.A. 1997. Avaliação do estado nutricional das plantas: princípios e aplicações. 2. ed. Potafos, Piracicaba.

MARSCHNER, H. 1995. Mineral nutrition of higher plants. Academic Press, New York.

Martuscello, J.A.; Fonseca, D.M.; Nascimento Júnior, D.; Santos, P.M.; Cunha, D.N.F.V.; Moreira, L.M.M. 2006. Características morfogênicas e estruturais de capim-massai submetido a adubação nitrogenada. Revista Brasileira de Zootecnia, Viçosa, 35, 3, pp. 665-678.

Mistura, C.; Fagundes, J.L.; Fonseca, D.M.; Moreira, L.M.M.; Vitor, C.M.T.; Nascimento Junior, D.; Ribeiro Junior, J.I. 2006. Disponibilidade e qualidade do capim-elefante com e sem irrigação adubado com nitrogênio e potássio na estação seca. Revista Brasileira de Zootecnia, Viçosa, 35, 2, pp. 372379.

Oliveira, P.P.A.; Trivelin, P.C.O.; Oliveira, W.S.; Corsi, M. 2005. Fertilização com N e S na Recuperaçào de Pastagens de Brachiaria brizantha cv. Marandu em Neossolo Quartzarênico. Revista Brasileira de Zootecnia, Viçosa, 34, 4, pp. 1121-1129.

Pereira, V.V.; Fonseca, D.M.; Martuscello, J.A.; Cecon, P.R.; Santos, M.V.; Braz, T.G.S. 2012. Biomass accumulation in mombasa guineagrass plants under different levels of nitrogen supply and plant densities. Revista Brasileira de Zootecnia, Viçosa, 41, 5, pp. 1118-1126.

Primavesi, A.C.; Primavesi, O.; Corrêa, L.A.; Silva, A.G.; Cantarella, H. 2006. Nutrientes na fitomassa de capimmarandu em função de fontes e doses de nitrogênio. Ciência e Agrotecnologia, Lavras, 30, 3, pp. 562-568.

Rodrigues, R.C.; Mourao, G.B.; Brennecke, K.; Luz, P.H. C.; Herling, V.R. 2008. Produção de matéria seca, relação folha/colmo e alguns índices de crescimento do Brachiaria brizantha cv. Xaraes cultivado com a combinação de doses de nitrogenio e potassio. Revista Brasileira de Zootecnia, Viçosa, 37, 3, pp. 394-400.

Rosolem, C.A.; Vicentini J.P.T.M.M.; Steiner, F. 2012. Suprimento de potássio em função da adubação potássica residual em um Latossolo vermelho do cerrado. Revista Brasileira de Ciência do Solo, Viçosa, 36, 5, pp. 1507-1515.

Ruan, J.; Wu, X.; Hardter, R. 1999. Effects of potassium and magnesium nutrition on the quality components of diffents types of tea. Journal of the Science of Food and Agriculture, Londres, 79, 1, pp. 47-52.

Santos, P.M.; Corsi, M.; Balsalobre, M.A.A. 1999. Efeito da frequencia de pastejo e da epoca do ano sobre a produção e a qualidade em Panicum maximum cvs. Tanzânia e Mombaça. Revista Brasileira de Zootecnia, Viçosa, 28, 2, pp. 244-249. 
Silva, S.C.D.; Bueno, A.A.D.O.; Carnevalli, R.A.; Uebele, M.C.; Bueno, F.O.; Hodgson, J.; Matthey, C.; Arnold, G.C.; Morais, J.P.G. 2009. Sward structural characteristics and herbage accumulation of Panicum maximum cv. Mombaça subjected to rotational stocking managements. Scientia Agricola, Piracicaba, 66, 1, pp. 8-19.

Silveira, M.C.T.; Nascimento Júnior, D.; Cunha, B.A.L.; Difante, G.S.; Pena, K.S.; Silva, S.C.; Sbrissia, A.F. 2010. Effect of cutting interval and cutting height on morphogenesis and forage accumulation of guinea grass (Panicum maximum). Tropical Grasslands, Cali, 44, 2, pp. 103108.

Silveira, M.L.; Vendramini, J.M.B.; Sellers, B.; Monteiro, F.A.; Artur, A.G.; Dupas, E. 2015. Bahiagrass response and N loss from selected $\mathrm{N}$ fertilized sources. Grass and Forage Science, Oxford, 70, 1, pp. 154-160.
Viana, E.M.; Kiehl, J.C. 2010. Doses de nitrogênio e potássio no crescimento do trigo. Bragantia, Campinas, 69, 4, pp. 975982.

Volpe, E.; Marchetti, M.E.; Macedo, M.C.M.; Lempp, B. 2008. Acúmulo de forragem e características do solo e da planta no estabelecimento de capim-massai com diferentes níveis de saturação por bases, fósforo e nitrogênio. Revista Brasileira de Zootecnia, Viçosa, 37, 2, pp. 228-237.

Xu, G.; Wolf, S.; Kafkafi, U. 2002. Ammonium on potassium interaction in sweet pepper. Journal of Plant Nutrition, New York, 25, 4, pp. 719-734. 